\title{
A CASE WITH OPISTHOTONUS: A RARE ETIOLOGY FOR A WELL-KNOWN FINDING
}

B. Cetin ${ }^{1}$, M. Onay², B. Binboğa², Ö. Kendir³, Ç. Damar ${ }^{4}$

${ }^{1}$ Ministry of Health, Cengiz Gökcek Maternity and Child Health Hospital, Pediatric Infectious Disease, Gaziantep, Turkey.

2Ministry of Health, Dr Ersin Arslan Education and Research Hospital, Interventional Radiology, Gaziantep, Turkey.

3Ministry of Health, Cengiz Gökcek Maternity and Child Health Hospital, Pediatric Emergency, Gaziantep, Turkey.

${ }^{4}$ Gaziantep University, Medical Faculty, Radiology, Gaziantep, Turkey.

\section{Background}

Opisthotonus is a type of abnormal posture due to muscle spasms. The condition is usually a sign of serious brain conditions, such as meningitis, tetanus, and trauma. In this article we present an adolescent with opisthotonus with a rare underlying disease.

Case

A 15-year-old Syrian boy from a border city of Syria (Cerablus), was brought to our emergency service with acute severe headache and hyperextension posture of head (Figure 1). One month ago, he had fallen from the motorcycle and a wound on the forehead was sutured in Cerablus without any tetanus prophylaxis. He had no fever or other recent illnesses. On examination, tonus of other muscles were normal. There wasn't trismus, he had a normal gag reflex response but he couldn't speak properly. Instead of high creatinine kinase levels, other laboratory tests and cranial CT were normal. Because of not having a history of proper vaccination, tetanus immune globulin and vaccine was administered. A mild sedation relieved the patient's symptoms and continued for seven days in ICU.
In the second week, significant improvement was seen. By further radiologic studies, we found an extensive spinal arteriovenous fistula in cervical and thoracic regions (Figure 2A, 2B and 2C).

After first findings had resolved, patient developed bilateral lower extremity flask paralysis. EMG showed peripheral neuropathy which was resolved spontaneously in two weeks. That was attributed to tetanus immune globulin.

The patient's family did not accept therapeutic angio intervention because of its risks and the case was discharged after fourth week. When this poster was prepared after 8 months from discharge, we learned that the patient is still living in Cerablus without any complaints.

Figure 1. Posture of the case at the time of admission

\section{Discussion}

Tetanus is an infectious disease characterized by severe muscle contractions caused by the toxin of Clostridium tetani bacteria. There are generalized, systemic, cephalic and newborn forms. Trismus and opistotonus position are typical in generalized form.

The development of spasm as opposed to the normal gag reflex in oropharyngeal stimulation with spatula, is a valuable finding for tetanus (positive spatula test). In the case of localized tetanus, the diagnosis may be omitted because the contractions can be subtle or can start within a limited number of muscle groups.
Spinal vascular malformations are rare and the most common clinical findings are back pain, sensory deficits, weakness in the extremities and bowelbladder dysfunctions. In our patient, that sudden onset clinical pattern was thought to be due to vascular malformation, self-limiting bleeding, or localized nerve stimulation.

Figure 2. Spinal arteriovenous malformation ( $A$ and $B$ : Conventional angio AP and lateral images, C: CT angio, coronal section image
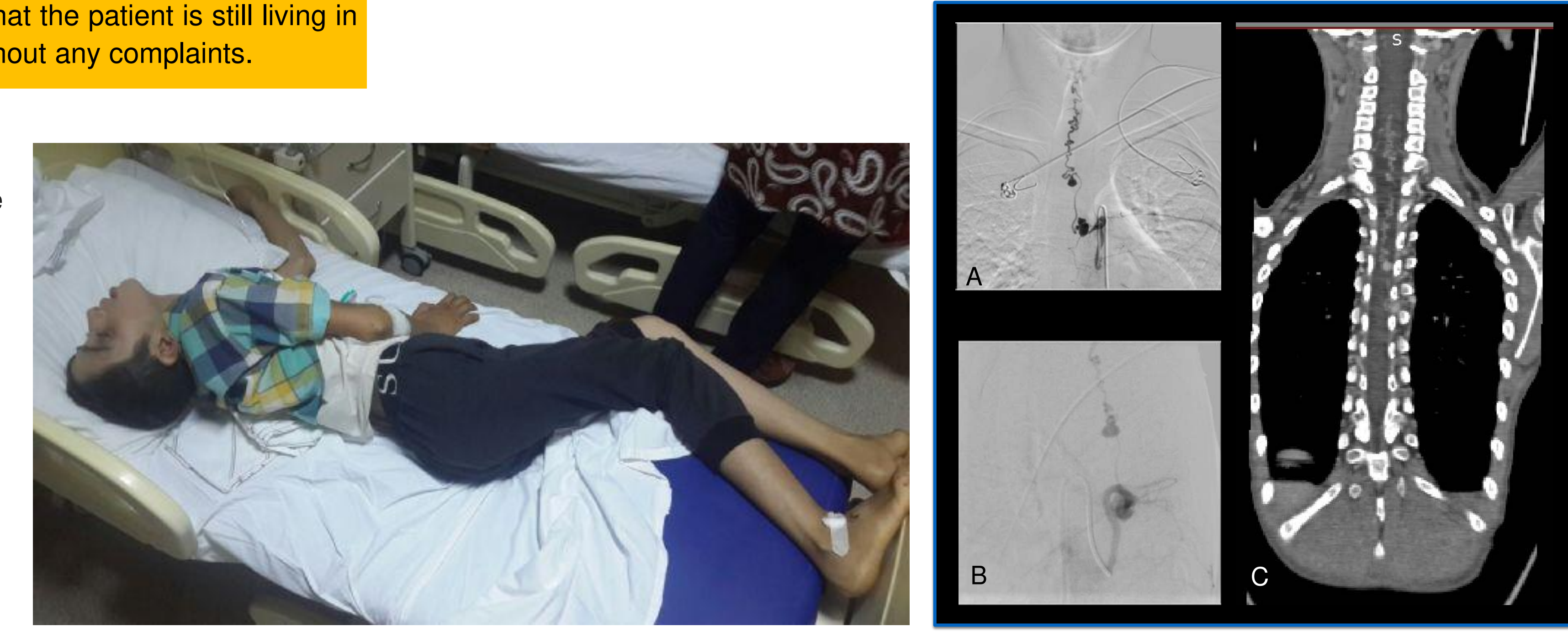